\title{
Mujeres víctimas de violencia de género: vivencias y demandas
}

\author{
Ainara Canto Combarro* \\ Iratxe Mier Villarías* \\ Clara Isabel Natividad Muñoz* \\ Raquel Pasadas Marroquí* \\ Zuriñe Romeo Perez* \\ *Fundación EDE \\ <gizaikerketak@fundacionede.org>
}

Egoera berbera bizi duten beste emakumeei sostengua emateko baliagarritasun handikoa da bikotekide edo bikote ohiaren genero-indarkeria pairatu duten emakumeen inguruko ezaguera izatearen aukera. Premisa hori oinarri, abiatu zen genero-indarkeriaren biktima izandako talde batzuen dinamizazioa testigantza eta kezkak trukatzeko, iritzia emateko kolektibo horrekiko prebentzio- eta eskuartze-arloko gabezien inguruan eta azaltzeko hobekuntza-proposamen batzuek. Artikulu honetan biltzen dira Genero-indarkeriaren biktima diren emakumeak: bizipen eta eskariak (2012) txostenaren ideia nagusiak. Txostena argitaratu zuen Eusko Jaurlaritzaren Genero Indarkeriaren Biktimei Laguntzeko Zuzendaritzak eta aipaturiko esperientzia horretatik azterlana burutu zuten EDE Fundazioaren Ikerketa Sozialeko Zerbitzuak eta Suspergintza Elkartearen Emakumeen Sailak.

\section{GAKO-HITZAK:}

Genero-indarkeria, emakumeen aurkako indarkeria, tratu txarrak, testigantzak.
Las mujeres que han sido víctimas de violencia de género por parte de su pareja o expareja representan una oportunidad de conocimiento inmensamente valiosa para apoyar a otras que pasan por su misma situación. Con esta premisa, se puso en marcha la dinamización de un grupo de víctimas de violencia de género que intercambiara testimonios y preocupaciones, opinara sobre las carencias en materia de prevención e intervención con este colectivo y plantearan propuestas de mejora. Este artículo recopila las principales ideas del informe Mujeres víctimas de violencia de género: vivencias y demandas (2012), publicado por la Dirección de Atención a Víctimas de Violencia de Género del Gobierno Vasco, y elaborado por el Servicio de Investigación Social de Fundación EDE y el Área de Mujer de Suspergintza Elkartea a partir de la experiencia señalada.

\section{Palabras Clave:}

Violencia de género, violencia contra las mujeres, maltrato, testimonios. 


\section{Introducción}

La violencia contra las mujeres es un hecho reconocido como problema social, un grave atentado a los derechos humanos de las mujeres y niñas, una preocupación que ha derivado en la puesta en marcha de diversas medidas, entre las que cabe citar la Ley Orgánica 1/2004, de 28 de diciembre, de Medidas de Protección Integral contra la Violencia de Género, o en el País Vasco, la Ley 4/2005, de 18 de febrero, para la Igualdad de Mujeres y Hombres, y su posterior modificación (Ley 3/2012), así como planes (Emakunde, 2014) u organismos -como el Observatorio Vasco de la Violencia Machista contra las Mujeres (Decreto 264/2011)- que tienen como finalidad la eliminación de este fenómeno universal.

La violencia de género tiene un carácter estructural, pues aunque las interacciones agresivas las protagonicen personas concretas en sus relaciones privadas, la explicación del fenómeno tiene que ver con la estructura patriarcal de la sociedad. Se entiende por violencia de género "la violencia que sufren las mujeres por el mero hecho de serlo" (Dirección de Atención a las Víctimas de la Violencia de Género, 2011a: 8), en el marco de unas relaciones de poder desiguales entre mujeres y hombres. Se trata de un tipo de violencia en el que el género de quien ejerce la violencia y de quien la recibe están íntimamente ligados a la violencia ejercida, dado que se basan en el interés, por parte de los hombres agresores, de mantener el control y superioridad sobre las mujeres.

La génesis de la violencia requiere que se tomen en cuenta un conjunto de factores que tienen diferente naturaleza e incidencia. Unos forman parte del macrosistema: la organización social/sexual, la organización del trabajo, los sistemas de creencias, las ideologías en relación con el sexo, los modelos culturales o los estilos de vida. Estos factores encuentran su correspondencia en modelos familiares y de pareja que pertenecen al nivel de microsistema. Además, hay que asociar estos factores a características psicobiológicas determinadas, las cuales -cuando interactúan con los demás factores enunciadospueden generar violencia (Fundación EDE, 2010).

En este sentido, existen diferentes formas de violencia: la ejercida por la pareja o expareja, la ejercida en el ámbito intrafamiliar (al margen de la pareja y expareja) y los delitos contra la libertad sexual (abuso sexual, agresión, acoso sexual e intimidación en el trabajo u otros espacios públicos, exhibicionismo, provocación sexual, corrupción de menores, prostitución forzada y trata de mujeres y niñas, y pornografía de menores) [Dirección de Atención a las Víctimas de Violencia de Género, 2011b].

Los datos disponibles sobre violencia de género han de ser considerados como una pequeña parte de la violencia de género existente, aquella que es posible contabilizar porque las mujeres deciden denunciar, pero quedan fuera de este análisis las distintas situaciones de violencia ejercidas hacia las muje- res y que no son denunciadas, y por tanto, quedan invisibilizadas.

En 2010, se registraron en la CAPV un total de 3.507 mujeres víctimas de violencia de género, el $68 \%$ de las cuales habían interpuesto una denuncia ante la Ertzaintza (Dirección de Atención a las Víctimas de Violencia de Género, 2011a). Según datos del estudio Violencia machista contra las mujeres en la CAPV: percepción, incidencia y seguridad (Fundación EDE, 2012b), el 7,5\% de las mujeres de 16 o más años residentes en la CAPV consultadas había sufrido violencia de género por parte de sus parejas o exparejas alguna vez en la vida, y el 1,19\%, la sufría en el momento de la encuesta. Tres de cada cuatro mujeres víctimas de violencia no lo habían denunciado.

Este mismo estudio, siguiendo los pasos dados por investigaciones previas (Cantera, Estébanez y Vázquez, 2009; Departamento de Acción Social, 2009), cuantifica también la incidencia de distintas manifestaciones de violencia socialmente menos visibles que suponen un abuso sobre las mujeres por el hecho de serlo, comportamientos que son especialmente invisibles y ocultos socialmente y que, en ocasiones, ni siquiera son asumidos como violencia. El estudio deduce que un $8,5 \%$ de las mujeres vascas consultadas habían sufrido alguna vez, por parte de su pareja o expareja, alguna de las situaciones de violencia planteadas, aunque ellas mismas no lo hubieran expresado abiertamente. Esta violencia no debe dejarnos indiferentes y debe ser visibilizada, ya que se trata una de las principales vulneraciones de los derechos humanos que afectan exclusivamente a las mujeres por el hecho de serlo. Según la Organización Mundial de la Salud (2005), la principal causa de muerte entre las mujeres de 16 a 44 años de edad es el asesinato a manos de sus parejas o exparejas, y siete de cada diez mujeres asesinadas en el mundo lo son a manos de sus parejas o exparejas.

Resultan especialmente interesantes los trabajos de investigación que han conseguido acercarse a este fenómeno desde una perspectiva cualitativa, poniendo el enfoque en la propia visión de las mujeres (Aparici y Estarellas, 2010; Ibáñez González, 2004). En este sentido, la Dirección de Atención a las Víctimas de Violencia de Género del Gobierno Vasco puso en marcha en 2011 un proyecto a partir del cual constituir y dinamizar un grupo de mujeres víctimas de violencia por parte de su pareja o expareja, con vistas a dar voz a estas mujeres y conocer su opinión para identificar posibles propuestas de mejora en la prevención e intervención con el colectivo. Un total de 28 mujeres que ya habían roto el vínculo afectivo con su agresor participaron en esta iniciativa. Se optó por trabajar con ellas a partir de la técnica cualitativa de los grupos de discusión, que permite potenciar el trabajo de reflexión, dando pie al intercambio de ideas y favoreciendo la generación de nuevas ideas y propuestas. Este artículo recoge las principales conclusiones extraídas del análisis de los grupos. 


\section{Las historias de maltrato}

No existe una única historia de maltrato, cada historia es única. Cada escenario es diferente, cada mujer tiene sus propias vivencias y cada una actúa en función de su propia realidad. Algunas historias duran mucho tiempo, otras son realmente breves, en algunas las agresiones físicas tienen un protagonismo radical, mientras que otras se caracterizan por el maltrato sibilino continuado. Algunas mujeres han optado por denunciar al agresor, mientras que otras no han llegado a hacerlo. En ocasiones terceras personas han intervenido en la ruptura, y otras veces ha sido el propio agresor quien ha acabado con la relación.

Aunque es difícil identificar el inicio del maltrato, durante el noviazgo suelen aparecer ciertas conductas agresivas que, sin embargo, las mujeres no relacionan con la violencia de género hasta tiempo después:

Es que realmente no te das cuenta ni cuando empieza. Tú estás viviendo el día a día. Cuando te empiezas a dar cuenta, ya es tarde.

No sé en qué punto pasa..., que te peguen una patada es normal, que te empujen es normal, que te tiren de un coche en marcha es normal..., porque algo habrás hecho... y cuando te das cuenta, es tarde de narices

Yo le di muchas oportunidades y yo ya le dije: “mira, yo ya otro año más así, no aguanto”. Y entonces fue cuando él comenzó a maquinar cómo hacer lo que hizo...

Las agresiones físicas están presentes en la mayoría de los casos y el fuerte componente de maltrato psicológico favorece que la historia de maltrato se extienda en el tiempo. Además, la soledad con la que han vivido un maltrato que han intentado mantener oculto es un elemento que se repite en los testimonios de las mujeres. El aislamiento al que acaban sometidas dificulta tomar conciencia y salir de la situación de maltrato.

Durante esos diez años nadie supo nada, ni mis padres ni nadie sabían nada de lo que me estaba pasando. Sentía vergüenza y no quería que nadie supiera nada.

Pero ¿cuál es el desencadenante o el momento en el que se toma conciencia de la situación como para dar el paso hacia la ruptura? Al igual que ocurre con el inicio del maltrato, no existe un único factor o momento concreto de toma de conciencia, sino que son distintos los factores que pueden desencadenar el final de una realidad que, en la mayoría de los casos, no se quería aceptar. Las mujeres identifican distintos indicadores que les ayudaron a darse cuenta de la realidad en la que vivían inmersas y contribuyeron especialmente a tomar la decisión de abandonar al agresor: caer en la cuenta de que ya no se es la misma persona, haber llegado a situaciones límite de violencia física (puñetazos, palizas) en las que se ve peligrar la propia vida, la vivencia de situaciones de humillación extremas (violaciones, agresiones delante de familiares), la red social más o menos cercana que observa un cambio emocional, entre otras. En el caso de las mujeres con hijos e hijas, el miedo a que éstos/as sufran actúa como detonante.

El momento de la ruptura con la pareja se caracteriza principalmente por el miedo al ‘qué dirán', la vergüenza de tener que exponerse, la incertidumbre de si se las creerá o si, por el contrario, sufrirán el cuestionamiento del entorno: en definitiva, una segunda victimización. Se describe el proceso como una carrera de fondo en la que hay que lograr ir sumando fuerzas para no volver atrás; de ahí que sea tan importante el apoyo de la red social próxima (familiares, amistades) o el soporte de los recursos especializados:

Y luego, cuando lo reconoces, lo dices; y tanta gente te cuestiona siempre, siempre...

El día que dices “lo dejo”, se te llena todo de entusiasmo, alegría, te entran ganas de cantar, vas por la calle como pisando fuerte... Pero el dinero, el juicio, el abogado de oficio... Es un tema muy duro, te ves sola muchas veces [...] Me he visto sin dinero para dar de comer a mis hijos; una vecina me daba, una amiga me dejaba...

El cambio es entendido como un avance y una mejora que simboliza, antes o después, libertad, tranquilidad, estabilidad, felicidad, autoconocimiento y reencuentro, perdón, orgullo y satisfacción, realización personal y profesional. Sin embargo, la inseguridad es algo con lo que hay que vivir durante mucho tiempo. Quizá por ello, el mayor deseo, el más repetido por muchas de ellas, sea vivir sin miedo, sin miedo a encontrarse con el maltratador, a sentir pavor al oír su voz, a mirarle a la cara. Lograr rebajar el estado de alerta permanente en el que viven:

Vivir sin fobias, sin pastillas, sin complejos [...]. No puedo pensar en lo bueno si primero no quito lo malo.

Vivir sin escudo, poder fiarme de otra persona.

\section{Las principales preocupaciones de las mujeres}

Aunque son diversas las preocupaciones de las mujeres que han sido agredidas por sus parejas o exparejas, cabe destacar algunas cuestiones que tienen una relevancia especial tanto en el proceso inicial como en la superación del maltrato y el futuro de estas mujeres.

\subsection{El inicio del proceso tras la ruptura con el agresor: una rosa con espinas}

Independientemente de cada caso, todas coinciden en que, tras la ruptura, comienza un duro proceso del que 
nunca fueron conscientes y que se enmarca dentro de un momento emocionalmente inestable, difuso y muchas veces contradictorio. Es un momento en el que algunas abandonan su domicilio o su entorno más cercano, por lo que se produce un desarraigo: cambio de vivienda, de municipio o de provincia. A esto se añade la necesidad inmediata de encontrar vivienda, trabajo o un nuevo colegio para los y las menores.

Con ello, comienza todo el proceso emprendido contra el agresor-denuncias; juicio rápido, con su consecuente estrés emocional; arduo proceso burocrático-, sin olvidar la impotencia o la incomprensión que surge en ocasiones cuando no pueden demostrar nada ante el sistema judicial, o el desamparo que experimenten a veces por parte de la ley. Es un momento en el que se sienten solas, aunque desde las instituciones se lance el mensaje contrario ("no estás sola"). Sienten que están paradas dentro de un mundo que gira a su alrededor de forma vertiginosa (policías, abogados y abogadas, psicólogos y psicólogas), en el que, además, deben tomar decisiones cruciales de manera precipitada, y así es muy fácil equivocarse:

Sientes que hay una maquinaria que se pone en marcha y tú eres un elemento, pero no sabes dónde ir.

Te mandan tomar decisiones en un momento en el que no estás nada ubicada, y puede que muchas veces nos equivoquemos.

Es, sin duda, una etapa que las mujeres viven con especial angustia y se trata del inicio de un proceso que pasa a alargarse considerablemente en el tiempo (acaban sintiéndose atrapadas en un proceso que parece no tener fin, ya que sigue habiendo juicios pendientes mucho tiempo después, los agresores incumplen las órdenes de alejamiento y deben enfrentarse de nuevo a ellos, o han de hacer frente a hipotecas y deudas) y al que las mujeres se enfrentan con las fuerzas diezmadas. Además, no siempre la actuación de los y las profesionales que intervienen en todo este proceso es la más correcta: frases desacertadas que pueden desanimar a la mujer a interponer la denuncia, falta de información que hace que las mujeres inviertan grandes esfuerzos para conseguir avanzar muy poco, muchas caras distintas a las que contarles una y otra vez la misma historia.

De ahí que las mujeres echen en falta dos cuestiones clave. De un lado, un acompañamiento personalizado por parte de las instituciones, es decir, que se les brinde una persona que sirva de referencia y ejerza de acompañante durante todo el proceso y de manera personalizada. Alguien con conocimientos específicos en materia de violencia de género, con información sobre los procesos a seguir y los lugares a los que acudir. No se trata exclusivamente de un apoyo psicológico, sino también de la labor que pueden ejercer, por ejemplo, educadoras y educadores sociales. De otro lado, demandan información clara y clave vinculada con la denuncia, los procesos judi- ciales, los recursos a los que acudir o los derechos con los que cuentan. Esta información resulta crucial en los primeros momentos, cuando existe una mayor confusión y cuando más decisiones hay que tomar sin apenas reflexión previa.

\subsection{Interponer o no la denuncia al agresor: la denuncia como dilema}

Denunciar o no al agresor es una de las cuestiones que más debate suscita, si bien existe un acuerdo en que la decisión está plenamente vinculada a la situación concreta de cada mujer, además de que cada una -en caso de decidir denunciar- debe elegir su momento. Parece también unánime la idea de que cualquier decisión es válida y que no puede culpabilizarse a ninguna por no poner una denuncia al agresor.

Mayoritariamente las mujeres participantes se han manifestado a favor de interponer denuncia y, en la medida de lo posible, cuando se produce la primera agresión. Se pronuncian así incluso aquellas mujeres que no interpusieron denuncia tras la primera agresión o nunca llegaron a ponerla:

Cada una tiene sus motivaciones, y en un momento dado tú no te sientes capaz, no puedes, no quieres o te lo hacen ver así. Pero luego te decides, o no te decides nunca. Pero lo que no puedes es culparte. Yo estuve 26 años casada con esta persona y luego denuncié.

En general, establecer la denuncia es un acto que genera inseguridad y duda por múltiples razones: el estado anímico en el que se encuentran, el desconocimiento sobre lo que puede ocurrir, la reacción del agresor a saberse denunciado o la vergüenza por el entorno. Resulta una preocupación para las mujeres, pues se trata de una decisión trascendental no sólo desde el punto de vista simbólico, sino porque a partir de ese momento el engranaje jurídico se pone en marcha y lo que parecía la salida es el inicio de una nueva lucha: las pruebas, los juicios, las sentencias. En cualquier caso, la denuncia marca un hito en el proceso.

Esta primera denuncia no siempre responde a las situaciones más violentas del maltrato sufrido, sino que está ligada a la fuerza que en ese momento se tenga, a "la gota que colma el vaso" o a la repercusión que puede tener sobre los hijos e hijas:

Después de diez años aguantando de todo, puse la primera denuncia. La primera denuncia fue realmente la menos importante de todo lo que me había ocurrido. Fue cuando me dejó con cinco euros en la cartera y los cuatro críos. Me quedé sin nada y ésa fue la primera que puse.

Tener menores y ser consciente de lo que están viendo es un factor que suele motivar a poner la primera denuncia. También los recursos en los que 
son atendidas (sanitarios, policiales) suelen motivar a poner la denuncia.

Las mujeres participantes en el grupo tienen claro que interponer la denuncia no siempre es totalmente beneficioso y puede colocar a las mujeres en riesgo, más si cabe cuando éstas no se han atrevido finalmente a hacerlo y es la policía la que abre atestado de oficio al observar indicios, con el agravante de que, en algunos casos, las mujeres no eran conscientes de que el proceso estaba ya en marcha. Una de las cuestiones que más preocupa a la hora de enfrentarse a una denuncia es el hecho de que las medidas de protección no estén plenamente garantizadas, lo cual genera un miedo difícil de asumir. Por ello, se demanda un mayor control en el momento en el que se procede a interponerla:

Creo que estamos animando mucho a denunciar, a denunciar muy pronto, y no está la infraestructura para que eso se dé: llegas al juzgado de violencia, y no es mi caso, pero sé de casos que, al final, igual te vuelves con la denuncia a tu casa, porque no es lo suficiente grave, o porque no había pruebas y se queda en un nada.

\subsection{Las condenas a los agresores: ineficacia e insatisfacción}

Hay un acuerdo unánime en que las medidas judiciales dictadas a favor de las mujeres son poco efectivas. Se rechaza, por ejemplo, el escaso grado de cumplimiento de las órdenes de alejamiento y, en general, éstas se consideran medidas que no protegen y que siguen dejando a las mujeres en situación de vulnerabilidad.

En cuanto a las condenas a los agresores, las mujeres las consideran demasiado lasas. No creen que la cárcel facilite la reinserción, aunque juzgan apropiado que los agresores cumplan condenas de prisión y, por lo general, tienden a demandar condenas más duras y que estén acompañadas de asistencia psicológica obligatoria. Las mujeres son favorables a los programas de reeducación de maltratadores como medida complementaria a la punitiva.

En los casos en los que el agresor ha cumplido condena de cárcel, una de las principales preocupaciones de las mujeres es el miedo y la impotencia que produce saber que el agresor saldrá de la prisión una vez cumplida su condena o cuando cuente con permisos penitenciarios. Además, las condenas de cárcel no compensan el sufrimiento vivido por las mujeres $y$, en ocasiones, pueden tener el efecto contrario al esperado.

Cuando me dijeron que iba a ir a prisión, se me calló el mundo encima [...], más que nada por mí, porque decía "este hombre va a estar allí seis meses comiéndose el coco entre cuatro paredes, y cuando salga, viene a por mí”. En ese momento, lo de la cárcel lo ves bien, ¿pero cuándo salga?
Las ordenes de alejamiento son una de las medidas más cuestionadas por las mujeres, pues casi en la totalidad de los casos los agresores las incumplen. Son medidas que, en gran parte, dependen de la voluntad del agresor y no de mecanismos judiciales, y dejan a la víctima como principal garante de su cumplimiento (por ejemplo, ellas deben informar si el agresor se acerca o llama por teléfono). De manera general, se cree que los agresores se saltan de forma consciente las medidas (pasan por delante del domicilio, las siguen, se quedan hablando con algún vecino) y que pueden hacerlo porque no son suficientemente restrictivas, no están suficientemente controladas, su quebrantamiento no tiene consecuencias inmediatas y porque se hace caso omiso cuando las mujeres informan de algún quebrantamiento. Por otro lado, las distancias de alejamiento establecidas se consideran insuficientes. En la mayoría de los casos, los agresores de las participantes en el grupo tienen órdenes de alejamiento de 1000200 metros, pero esa distancia se antoja incumplible cuando víctima y agresor viven en un pueblo pequeño, o cuando el agresor vive relativamente cerca de la víctima. Además, los agresores tienen la posibilidad de recurrir la distancia para que se acorte, de manera que priman más los derechos del agresor (se tienen en cuenta dónde vive, por dónde se mueve) que el riesgo de que se repita otra agresión.

En general, estas situaciones generan sentimientos de impotencia y rabia, de inseguridad y desprotección, siendo las mujeres las que tienen que defender una y otra vez su inocencia. El sentimiento de culpabilidad está también presente en estos casos.

\subsection{Las medidas de protección a las víctimas: necesarias pero injustas}

Las mujeres consideran que las medidas de protección a las mujeres son necesarias y vitales para preservar su seguridad, y quienes se benefician de ellas las aprecian. Por todo ello, consideran que se deben reforzar, y más en tanto en cuanto no se intensifiquen judicialmente los controles a los agresores.

En el grupo de mujeres, algunas han contado con escolta cuando el agresor ha salido de la cárcel, y otras, con seguimiento domiciliario o telefónico. Las medidas de protección son una forma de ofrecer más seguridad, pero convierten a las mujeres en cautivas de su propia protección. Aun así, entienden que no pueden renunciar a ellas mientras no se intensifiquen también las medidas judiciales de control al agresor. Es decir, consideran que sería más justo que, desde el ámbito judicial, centrasen el foco de control también en el agresor, que fuera él el vigilado, controlado o seguido, que fuera él quien tuviera que dar cuenta de cada uno de sus pasos o sintiera la vergüenza en su propia piel:

Las medidas deben aplicarse a ellos. Cuando no hay una denuncia, ahí no se puede agarrar nadie a nada, pero sí cuando ha habido una sentencia. En estos 
casos, directamente que se vaya a una psicóloga y que directamente le pongan a él las medidas de control. Y que la obligación de presentarse o no presentarse, o de recibir ayuda, sea para ellos. También para nosotras, como víctimas, pero para ellos el control [...]. Una reinserción se da realmente desde dentro para fuera, no desde fuera para dentro.

\subsection{El bienestar de los hijos e hijas de las mujeres agredidas: los y las menores también son víctimas}

En el caso de las mujeres con hijos e hijas -sobre todo cuando se trata de menores de edad-, la preocupación por cómo hayan podido vivir la historia de maltrato y cómo les afectan las distintas circunstancias, la conducta del agresor con sus hijos e hijas, o si los y las menores deberían ver o no a su padre son cuestiones realmente angustiosas.

Sin duda, todas las mujeres muestran una gran preocupación por cómo ha podido incidir haber vivido situaciones de maltrato en la infancia: en definitiva, sobre las secuelas que puede dejar el maltrato. En los casos más extremos, se han detectado conductas violentas en los y las hijas en la etapa adulta -en algunos casos, hacia la propia madre-, algo que se relaciona con que hayan vivido en la infancia en un hogar donde el maltrato estaba presente.

En la mayoría de los casos se ha tratado de ocultar el maltrato sufrido (no contar los episodios de maltrato, esconder las heridas, alejarles de los momentos de violencia), salvo cuando los y las menores han estado presentes o han sido víctimas de la propia agresión, si bien parece que el ocultamiento, muchas veces, se ha vuelto en su contra:

El papel de madre lo llevamos hasta el último momento. Yo no quería que fuesen a los juicios, pero él los ha involucrado sólo por cuestiones monetarias. Al final, te pones a pensar y dices: “¡si es que se está volviendo en contra mía!”. Esa manera de actuar, de la que no me arrepiento, te pones a valorar y va en contra tuya. Porque mis hijos no vieran el maltrato, él se ha quedado con el piso y yo me he tenido que ir... Yo no sé si ese modo de actuar es el correcto o no, ni cuándo es el momento de decirle a un hijo lo que está ocurriendo.

Una de las consecuencias más duras de la ocultación es que, en ocasiones, las mujeres han sido culpabilizadas por sus hijos e hijas cuando se hacen mayores. Las acusan de no haber puesto fin al maltrato antes 0 de haberles obligado a seguir teniendo relación con su padre.

Existe acuerdo entre las mujeres en pensar que los hijos e hijas son mucho más conscientes de la situación de lo que ellas pensaban, aun tratándose de niños y niñas pequeñas. Además, lo que sí parece claro es que la mayoría arrastra consigo el sentimiento de culpabilidad por haber ofrecido a sus hijos e hijas un entorno hostil durante la infancia:
Hay una cosa que no sé si a vosotras os pasa: es ese punto de “¿cómo lo he permitido?”. Eso es algo que jamás podré perdonarme.

Otro de los asuntos que generan debate e incertidumbre es el hecho de si los y las hijas deberían tener contacto o no con el agresor. En este sentido, se plantean tres cuestiones clave: el cumplimiento de los regímenes de visita, la educación o el modelo que ofrecen los padres agresores, y la colisión entre los derechos del padre y los derechos de niños y niñas. Éste es un tema que preocupa a las mujeres y produce ansiedad:

Yo firmé un régimen de visitas de mutuo acuerdo, pensando que el que fuese un mal marido no tenía nada que ver con que fuese un mal padre y que $\mathrm{mi}$ hijo tenía derecho a tener un padre... Y ahora lo estoy incumpliendo..., porque es un proceso [en el] que te das cuenta poco a poco, igual que sales del maltrato... De repente, un día dices "ipero yo estoy zumbada!", y ya es tarde.

Aunque la custodia de los hijos e hijas está en manos de la madre, tras el juicio de divorcio o las medidas judiciales para hijos/as extramatrimoniales se establece un régimen de visitas para el padre que ellas deben cumplir, independientemente de la voluntad de los y las menores. En este punto, las mujeres se sienten atrapadas en el dilema de si es bueno que sus hijos e hijas vean al agresor y convivan con él, si será una buena influencia, si deben o no cumplir lo que establece la ley. No existe un acuerdo sobre cómo debe actuarse, y existen experiencias muy distintas en torno a esta cuestión. Algunas mujeres consideran que si el padre no ha hecho daño a los menores debe poder disfrutar de su régimen de visitas, mientras que otras -bien porque el padre ha mostrado conductas violentas, o bien porque no conciben que un agresor tenga derechos y potestad sobre la infancia- han optado por incumplir el régimen de visitas. En otros casos, se cumple lo establecido por la ley, aunque no estén de acuerdo.

Sin embargo, existe acuerdo en que debería prevalecer la prevención. Especialmente contundentes se muestran las madres cuyos hijos o hijas han sufrido acoso sexual o maltrato por parte del agresor y que, en algunos casos, no tienen cómo probarlo. Para ellas, no hay duda: lo que sea para "salvar" a sus hijos e hijas; pero ciertamente en esta tarea se sienten solas e incomprendidas.

Además de las conductas violentas que los agresores pudieran llegar a tener con sus hijos e hijas, a las madres les preocupa el tipo de educación que les pueden ofrecer o los modelos de referencia que suponen. Se coincide en que determinados patrones y conductas no son una buena influencia, y aunque los y las menores pasen gran parte de su tiempo con la madre, resulta preocupante en qué medida puede manipular el agresor.

Sin duda, lo que subyace constantemente en el discurso de las mujeres es la yuxtaposición entre 
los derechos del padre a ver a sus hijos e hijas, y los derechos de la infancia a vivir en un entorno protegido y saludable $o$ a disfrutar de ambos progenitores. En este sentido se reivindica una y otra vez que los derechos de la infancia y la adolescencia sean tenidos en cuenta, que la opinión de los y las menores sea escuchada, sobre todo si han estado presentes cuando se producían las agresiones, o cuando son ellos o ellas mismas quienes declaran no querer ver a su padre. Las mujeres perciben que actualmente los derechos del maltratador pesan más que los de la infancia y la adolescencia. En suma, las mujeres reivindican que los y las menores sean considerados también víctimas de la violencia, y con ello, se establezcan mejores medidas de protección para las criaturas:

\begin{abstract}
El mayor defecto que tiene toda esta historia son los niños. Nadie ve a los niños y les ponen en brazos de los maltratadores. Un maltratador sólo quiere a un niño para hacer daño a la madre. Queda un camino brutal por hacer: reconocer a los hijos como víctimas de maltrato.
\end{abstract}

En opinión de las madres, la consideración de los y las hijas como víctimas requiere un mayor número de recursos de apoyo a la infancia y la adolescencia que ha sufrido maltrato en estos términos (haber visto directamente agresiones hacia su madre o haber sufrido directamente agresiones, por ejemplo), ya que se detecta una carencia en este campo (necesidad de apoyo psicológico y terapias). De hecho, los pocos casos en los que los y las niñas han sido atendidos en recursos terapéuticos especializados a la par que sus madres han sido muy apreciados, pues se considera imprescindible que este trabajo se haga al mismo tiempo; de lo contrario, las mujeres van saliendo y las criaturas, en cambio, se quedan enquistadas en la experiencia del maltrato.

\subsection{Los problemas económicos y la vinculación económica con el agresor: el empobrecimiento, otro lastre más}

Otro de los lastres de mayor peso que las mujeres que han sufrido situación de maltrato arrastran es el empobrecimiento económico, que en muchos casos llega a límites de dependencia extrema. Además, en ocasiones, ya existía una dependencia económica previa, lo que dificulta aún más la situación.

Algunas mujeres corren con los gastos íntegros de la hipoteca que suscribieron con el agresor, mientras que otras deben hacer frente a deudas adquiridas (préstamos personales, por ejemplo), incluso cuando el agresor ya ha fallecido. Por otro lado, se detectan numerosos casos en los que el agresor no pasa la pensión alimenticia de sus hijos e hijas, o en los que, aun pasándola, no se encarga de otro tipo de gastos derivados de la manutención (gastos extraordinarios, extraescolares):

De lo que no se hace cargo es de ningún gasto extra. “¿Inglés? La niña no necesita inglés”, ni al parecer necesita extraescolares, ni libros... Yo ya paso de pedirle nada.

El vínculo económico que sigue ligando a la víctima con su maltratador es un desgaste extra para las mujeres en todo este proceso. Pelear por que el padre se haga cargo de los gastos de las criaturas supone, incluso, un gasto económico, por ejemplo, cuando se contrata a un abogado o abogada para que se encargue de luchar por algo que debería ser de obligado cumplimiento.

Se habla también de lo irrisorias que son algunas pensiones alimenticias y de lo importante que es que la justicia vele por el bienestar de los y las menores, así como de que se controle, en mayor medida, los recursos económicos de los agresores.

Otra de las preocupaciones está relacionada con el hecho de que, si bien una vez existe sentencia de divorcio, las mujeres, en algunos casos, tienen derecho a percibir una pensión compensatoria (siempre que exista un desequilibrio económico respecto al marido), pero renuncian a ella para romper el vínculo con el agresor, cuestión que actualmente (Ley $27 / 2011$ ) las priva del derecho a percibir la pensión de viudedad cuando éste fallece.

No en todos los casos las ayudas económicas son accesibles. Los procesos para cobrarlas son complejos, tediosos; los requisitos no siempre contemplan la diversidad de situaciones y se evidencia que algunas de las ayudas 'estándar' no son útiles para resolver problemas característicos de las mujeres víctimas de violencia de género. En este sentido, las ayudas económicas a las mujeres víctimas de la violencia de género (Orden del Consejero de Interior de 30 de mayo de 2011) son apreciadas por las mujeres, en tanto en cuanto las consideran una ayuda para quienes, por su edad, falta de preparación u otras dificultades sociales añadidas, tienen especialmente difícil su incorporación al mercado laboral. Reclaman mayor información sobre dichas ayudas por parte de las trabajadoras sociales.

Las mujeres también se muestran preocupadas por su inserción laboral, especialmente las que tienen más de 45 años. En cuanto a las medidas de fomento del empleo (prioridad para el acceso a los programas de empleo y formación) [Decreto 329/2003], consideran que son insuficientes, $y$ que las subvenciones para su contratación no animan a los y las empleadores a contratarlas.

\subsection{El apoyo social e institucional: ellas se sienten solas}

En ocasiones, las mujeres que han sufrido agresiones se sienten doblemente victimizadas: por el agresor y por la sociedad en su conjunto. Esta segunda victimización se produce cuando el entorno no entiende su situación, las culpabiliza por no haber salido antes del maltrato o las juzga. Existe una incomprensión 
social sobre las situaciones de maltrato que permite juicios morales hacia las mujeres.

Aunque en la sociedad va calando cada vez más el mensaje de la lacra de la violencia de género, las mujeres perciben que sigue siendo un tabú, ya que el entorno (vecinos, amistades) no acaba de implicarse, y siguen existiendo testigos mudos del maltrato, que no reaccionan y miran hacia otro lado. Existe una indiferencia social. Además, algunos estereotipos sociales juegan en contra de las mujeres agredidas, ya que aquellas que no entran dentro del 'estándar de mujer maltratada' son aun más incomprendidas. En este sentido, reclaman fervientemente una mayor sensibilización dirigida a la infancia y la adolescencia, pues sólo desde edades tempranas pueden atajarse las conductas violentas y sentarse las bases de la igualdad entre mujeres y hombres.

Igual de preocupante resulta el insuficiente apoyo institucional, ya que, aunque se percibe un gran avance en materia de violencia de género, siguen existiendo vacíos legales y sociales a los que la Administración no da respuesta: los requisitos para el acceso a las ayudas no siempre responden a sus realidades, pueden darse incompatibilidades $y$, en algunos casos, se establecen cupos que restringen el acceso a gran parte de las mujeres.

\section{Uso y evaluación de los recursos}

Las mujeres participantes evaluaron también los recursos públicos esenciales que están a su disposición en los casos de violencia de género.

\subsection{Los recursos policiales}

Los recursos policiales son uno de los primeros con los que se topan muchas de las mujeres víctimas de violencia de género, y lo utilizan en distintos momentos de su proceso de superación de la historia del maltrato. A menudo la policía acude al domicilio de las mujeres cuando algún familiar, conocido o vecino informa sobre un posible episodio de violencia (generalmente grave); pero la comisaría es también el recurso al que acuden las mujeres para denunciar por primera vez su situación y al que vuelven, muchas de ellas, para poner en conocimiento de los y las agentes nuevas amenazas o quebrantamientos de órdenes de alejamiento.

En general, las mujeres participantes en el grupo hablan de una mejora en la atención prestada desde este recurso en los últimos años, probablemente muy vinculada al trabajo de formación y sensibilización que se ha hecho con el cuerpo policial, así como a la especialización de agentes en materia de violencia de género. Puede decirse que se ha pasado de culpabilizar a las mujeres a acompañarlas en el proceso de denuncia. Se valora la atención y el trato prestado, la cercanía, la implicación personal, la información proporcionada sobre los recursos existentes y los pasos a dar, o el seguimiento en el tiempo mediante llamadas o visitas domiciliarias.

No obstante es importante señalar que la calidad en la atención aun hoy no se ve garantizada en todos los casos. La insuficiente cobertura del personal especializado en violencia de género pone de manifiesto la importancia de incrementar el trabajo de sensibilización del conjunto de profesionales: los y las profesionales especializados en la materia no parecen cubrir todos los turnos o no son sustituidos por un perfil similar; y falta sensibilización entre quienes no se han especializado en violencia género.

Sería importante que los y las agentes y los protocolos de actuación consideraran la sensación de 'bloqueo' que las mujeres aseguran sentir en la comisaría, fruto del pánico, que no les permite ni contar los hechos tal cual han sucedido, ni tampoco entender y procesar la información que se les ofrece. En ocasiones, se sienten incomprendidas, avasalladas, y desconocen qué es lo que más les conviene. A ello se une el sentimiento de soledad y angustia después de denunciar. Así, las mujeres optan a veces por no denunciar, o por negarlo todo en los casos en los que es la policía quien ha acudido al domicilio tras una llamada.

Otra de las cuestiones que preocupan especialmente a la mujeres es que el agresor sea avisado pocas horas después de poner la denuncia, lo cual representa un peligro para la mujer denunciante, ya que no en todos los casos se activan medidas suficientes de protección para ellas e incluso, en ocasiones, no se las informa sobre la notificación al agresor, por lo que algunas vuelven al domicilio sin ser conscientes de que el agresor está informado de su denuncia. Se señalan también, las pocas posibilidades de anonimato y confidencialidad en los municipios pequeños.

\subsection{Los recursos judiciales y la asistencia jurídica}

En cuanto a los recursos judiciales y la asistencia jurídica, se señalan carencias o fallos que evidencian debilidades del sistema con consecuencias sobre las víctimas.

La existencia de un juicio rápido se considera positiva, pero se critica el largo tiempo de espera en el juzgado, el mal rato que deben pasar las mujeres al tener al agresor a pocos metros $\mathrm{y}$, principalmente, los espacios inadecuadamente habilitados en los que, aun no existiendo contacto físico o visual, se escucha todo lo que dice el agresor (la negación de los hechos, su falta de arrepentimiento). Además, se trata de un juicio marcado por un fuerte contexto emocional, por los acontecimientos sucedidos en muy pocas horas, y las mujeres se sienten desorientadas dentro de un entorno hostil al que no están acostumbradas. 
Sin embargo, el proceso judicial va más allá del juicio rápido. Este proceso judicial es lento y se dilata en el tiempo. Supone un desgaste para las mujeres, por los múltiples juicios en los que se ven involucradas a lo largo del proceso, y en estos casos la incomprensión del sistema aumenta y también la impotencia con respecto a determinadas incongruencias, como el diferente funcionamiento de los juzgados de instrucción y del juzgado específico de violencia de género, o la indefensión ante un sistema que no comprende su historia desde la globalidad.

Al comienzo del proceso judicial, las mujeres se sienten arropadas, de manera que todo resulta más sencillo (denuncia, juicio rápido), pero con el tiempo perciben que desaparece ese apoyo, mientras que su proceso judicial sigue en marcha; los juicios penales se aplazan, las resoluciones tardan en llegar, se quebrantan las órdenes de alejamiento y es necesario volver a poner una denuncia y un nuevo juicio. Además, los tiempos para resolver los juicios pendientes no siempre coinciden con los tiempos de 'curación' de las mujeres, y a menudo interrumpen su proceso. Por ello, se denuncia la lentitud de la justicia y las graves consecuencias que conlleva.

Se cuestiona también la facilidad que tienen los agresores para poner contradenuncias, especialmente si tienen una posición económica acomodada. Es decir, el maltratador, a veces asesorado legalmente, decide poner una denuncia contra la mujer por denuncia falsa, alegando en algunos casos que es ella quien maltrata o incluso que no está bien psicológicamente, y solicitan una prueba psicológica. En esta línea, se señala también lo imprescindible que resulta tener pruebas del maltrato para que la denuncia prospere.

Pero una de las cuestiones que suscita mayor incomprensión e insatisfacción es la falta de profesionalización y especialización de algunos abogados y abogadas en materia de violencia de género, advirtiéndose grandes diferencias entre las mujeres que han tenido una defensa especializada en la materia y las que no. En este sentido, existen diferencias entre la justicia gratuita y la privada, ya que se critica a los y las abogadas de oficio por su falta de sensibilización, el poco interés mostrado por el caso o la falta de seriedad al abordarlo.

En los casos en los que las mujeres han contado con letradas o letrados con formación específica en violencia de género o experiencia suficiente en la materia, la satisfacción es alta. Además, en estos casos no sólo se les ha ofrecido una buena defensa, sino que se valora especialmente la información ofrecida en materia de violencia de género (protocolos, acceso a recursos y ayudas públicas).

\subsection{Recursos sanitarios}

Se advierten dos situaciones en las que las mujeres acuden a los recursos sanitarios. Por un lado, como consecuencia de un episodio de violencia física o sexual por parte de la pareja; y por otro, de manera más meditada, sin ser consecuencia inmediata de una agresión. En el primer caso, las mujeres muestran una mayor desorientación y tienen recuerdos algo difusos, debido a la situación de alto estrés y ansiedad. En el segundo, los recuerdos son más nítidos y la evaluación parece más positiva.

Las mujeres están satisfechas con la rapidez y discreción del proceso de atención cuando se ha sufrido una agresión, con que se realicen los reconocimientos oportunos y con que se faciliten los partes de lesiones. Sin embargo, aunque este proceso es rápido, se destaca lo difícil que resulta dejarse hacer fotos de los moratones, el temor a no ser creída por el personal, la inseguridad y el tener que ir de un lado a otro sin tener muy claro nada. Pero, ante todo, se destaca negativamente que no exista una atención psicológica en el momento en el que una mujer acude a los recursos sanitarios alegando haber sufrido violencia de género. En especial, las mujeres hablan de cómo, tras todo el proceso de atención sanitaria, deben enfrentarse a la duda de denunciar o no denunciar, y en ese momento vuelven a sentirse solas y desorientadas.

\subsection{Recursos psicológicos}

Los recursos psicológicos están bien considerados por las mujeres que han hecho uso de ellos. Estos recursos son, por lo general, de responsabilidad pública y están gestionados por entidades privadas especializadas en la atención a víctimas de violencia de género ${ }^{1}$, si bien en algunos casos se ha recurrido también a otros recursos privados o no especializados.

La mayoría de las mujeres del grupo han podido acceder tanto a atención psicológica individual como a intervención de carácter grupal, y ambas modalidades son calificadas muy positivamente por las mujeres participantes en el grupo. La atención psicológica se recibe principalmente al comienzo del proceso (una vez se ha dado el paso de denunciar, de dejar el domicilio), aunque el periodo durante el cual se recibe dicha atención varía en función de la historia de cada una o del recurso en el que haya sido atendida, entre otros factores.

Se valora la atención y el trato recibido, así como la profesionalidad de quienes trabajan en estos recursos, que tiene su reflejo en el hecho de no juzgar a las mujeres o en el gran conocimiento en materia de género. También es positivo el hecho de que los y

${ }^{1}$ Algunos de los recursos mencionados son: el Servicio de Atención a las Víctimas (SAV) y el Servicio de Atención Telefónica 24 horas 900840 111, ambos dependientes de la Dirección de Atención a las Víctimas de la Violencia de Género; Ayuda a la Mujer Maltratada (servicios sociales municipales); el Programa de Asistencia Psicológica a Víctimas de Malos Tratos y Agresiones Sexuales de la Diputación Foral de Bizkaia, gestionado por Zutitu; y el Programa de Intervención Familiar Especializado en Violencia contra las Mujeres en el Ámbito Doméstico de la Diputación Foral de Bizkaia, gestionado por Suspergintza. 
las especialistas no se centren de manera exclusiva en el maltrato, sino que traten de indagar más allá, atendiendo a distintos ámbitos de la vida.

En general, se definen como recursos más que necesarios, incluso imprescindibles para superar la experiencia vivida, y se resalta la importancia de haber descubierto este tipo de recursos, y lo central que han sido o están siendo en su proceso de recuperación. Pero, sobre todo, son recursos considerados positivos, porque las mujeres encuentran en ellos el espacio en el que abrirse y liberarse. Son, además, una clave para tomar conciencia de su situación, de las experiencias vividas, una forma de entender lo que les pasa. Igualmente, estos recursos ayudan a las mujeres a aprender a valorarse a sí mismas y encuentran en ellos la posibilidad de identificarse con otras mujeres que han vivido situaciones similares o que se encuentran en un proceso semejante.

Con el paso del tiempo, las mujeres que sienten haber superado la situación de maltrato reconocen que el apoyo psicológico ha sido fundamental para llegar hasta el final y pasar página. Sin embargo, es importante resaltar que muchas veces existe un proceso inicial de negación en el que las mujeres no quieren asumir que necesitan atención psicológica -si bien, una vez superado, se sienten realmente agradecidas-. En esta misma línea, en algunos casos, se detecta que la falta de consciencia sobre su situación de víctima de violencia de género impide o disuade a algunas mujeres de acercarse a este tipo de recursos. En este sentido, es fundamental la labor educativa que se realiza previamente a la atención psicológica, y que supone una toma de conciencia para las mujeres, un proceso en el que informarse de la violencia de género y hacerse conscientes de su realidad.

Por otro lado, y aunque no de manera generalizada, algunas mujeres han mencionado su preocupación o temor inicial a que las apreciaciones sobre su situación emocional puedan venirse en su contra, por ejemplo, en la lucha por la custodia de los hijos y las hijas, temor que suele disiparse en la medida en que se comienza la terapia, y que denota, una vez más, que constantemente se sienten cuestionadas.

Aunque los recursos psicológicos como tales son apreciados, existen algunas cuestiones vinculadas con la falta de información sobre la asistencia psicológica, con las posibilidades de acceso a los recursos psicológicos especializados o con la frecuencia de las sesiones terapéuticas que son criticadas por las mujeres: en los momentos iniciales, no han tenido suficiente información sobre los recursos psicológicos (las distintas opciones existentes, el lugar al que acudir); la atención psicológica inicial por parte de los recursos públicos de atención especializada (asistencia psicológica de los servicios sociales) se demora demasiado; la frecuencia con la que se asiste a las terapias es demasiado reducida y la atención psicológica se va dilatando en el tiempo (cuanto más tiempo pasa, menos sesiones); en ocasiones no se facilita una atención adaptada a las necesidades concretas de cada mujer.
Por último, cabe señalar la poca atención psicológica que parecen haber recibido los y las hijas de las mujeres participantes. En muy pocos casos parece haber existido este tipo de atención, y en otros, es ahora cuando los propios hijos e hijas, al crecer, la demandan. Se advierte una falta de conocimiento sobre la existencia de recursos especializados en atención a menores víctimas de violencia de género. Es por ello por lo que se acude a psicólogos privados por iniciativa de las madres, donde la adecuación de la atención depende del conocimiento o especialización que el o la profesional tenga en este tipo de casos, y en especial, del poder adquisitivo de la madre, que en muchos casos no puede permitírselo por mucho tiempo, o ni siquiera planteárselo.

\subsection{Recursos residenciales de acogida}

Son muy pocas de las mujeres participantes que han hecho uso de los pisos de acogida. En algunos casos, se señala no haber tenido información sobre este tipo de recursos pero, en la mayoría de los casos, quienes contaban con una red social de apoyo han rechazado esta opción, al preferir estar con familiares o amistades. Es por ello por lo que este tipo de recurso parece ser más utilizado por las mujeres inmigrantes que no cuentan con red social de apoyo.

Incluso en casos en los que no existía red social alguna, las mujeres participantes señalan haber preferido no acudir a los pisos de acogida. Los motivos están vinculados con el miedo a ir a un lugar desconocido con una niña recién nacida, el mensaje negativo que se le lanzó sobre dicho recurso, el encontrarse sin nada de dinero para ir al recurso o la inexistencia de apoyo psicológico en ese momento.

Alguna de las mujeres que han hecho uso del recurso critican el entorno en el que se encontraba el alojamiento, ya que era fácilmente localizable por el agresor ("todo el mundo sabe dónde te llevan si no tienes dónde ir") y no era una zona segura, algo fundamental en un momento en el que lo que más se aprecia es la seguridad. En cualquier caso, algo que preocupa sobre los pisos de acogida es la dificultad de tener que tomar una decisión inmediata (que, por lo general, coincide con todo un largo día en el juicio rápido) y tener que justificar su situación de maltrato mediante denuncia u orden de alejamiento.

\section{Algunas propuestas lanzadas por las mujeres participantes}

A continuación se señalan algunas de las sugerencias planteadas por las mujeres participantes en los grupos de discusión.

\subsection{Información y orientación}

- Poner en marcha un único recurso que informe de todo ('ventanilla única') o, al menos, uno sólo en cada uno de los ámbitos institucionales. 
- Aumentar la coordinación entre los distintos recursos existentes.

- Proporcionar información y asesoramiento adaptado a las necesidades concretas de cada mujer.

- Ofrecer a cada mujer una persona orientadora desde el momento en el que se acude a una comisaría o a un centro de salud.

- Realizar un seguimiento del caso concreto de cada mujer tanto en el momento inicial (día en el que se pone la denuncia) como en las sucesivas semanas.

- Informar a las mujeres sobre las consecuencias que puede tener el hecho de denunciar o de abrirse un atestado policial.

- Incidir en una mayor especialización y formación de todos los recursos que atienden a las mujeres víctimas de violencia de género.

- Publicitar más el Servicio de Atención Telefónica 24 horas.

- Publicitar más el Servicio de Asistencia a la Víctima (SAV).

- Mejorar la información sobre las ayudas sociales y económicas en el resto de recursos no específicos.

\subsection{Educación y sensibilización}

- Formar al profesorado para sensibilizar al alumnado en esta materia, en especial a las adolescentes y jóvenes.

- Prestar más atención en los centros educativos a la educación emocional.

- Trasladar a las aulas los testimonios de mujeres víctimas de violencia de género (previa selección de idoneidad de las mujeres y con entrenamiento).

- Elaborar guías educativas sobre igualdad orientadas a las familias con hijos e hijas pequeñas (como las que existen para sensibilizar sobre otros asuntos).

- Informar mejor a la población sobre cómo actuar ante un caso conocido de violencia de género o ante una sospecha (pasos a dar, qué no hacer).

- Incidir en la formación y sensibilización de los medios de comunicación sobre el tratamiento de la violencia contra las mujeres.

- Crear una asociación de mujeres víctimas de violencia de género con vistas a aunar esfuerzos en la defensa de sus intereses y mantener un vínculo entre las mujeres que han sufrido maltrato.

\subsection{Sistema judicial y de asistencia letrada}

- Agilizar los procesos judiciales.

- Reforzar la coordinación entre los juzgados.
- Prestar asistencia letrada gratuita a todas las mujeres víctimas de violencia de género (eliminando los baremos económicos que limitan el acceso gratuito al servicio).

- Considerar las cargas (hipotecas, menores) en el cómputo de la renta que determina el acceso a la justicia gratuita (la situación actual puede inhibir denuncias).

- Priorizar la toma en consideración de las necesidades y rutinas de los y las menores y las madres a la hora de determinar los horarios de visita de los padres (y no al revés).

- Citar al agresor y a la víctima en días diferentes.

- Reducir las horas que las mujeres deben pasar en el juzgado durante el juicio rápido.

- Prestar servicio de guardería donde atiendan a los y las menores mientras se celebra el juicio rápido.

- Habilitar el juzgado, principalmente la sala de espera, para garantizar la intimidad de las mujeres víctimas y la separación del agresor.

- Incidir en la formación y especialización de los jueces y juezas.

- Incidir en la formación y especialización obligatoria de abogados/as de oficio que defiendan los casos de violencia de género.

- Garantizar que en la sentencia de divorcio se desvincule económicamente a la víctima de su agresor (haya separación de bienes o bienes gananciales si estaban casados o tenían hipoteca).

- Ejercer un mayor control de las órdenes de alejamiento (y de los movimientos) mediante medidas disuasorias telemáticas (pulsera de vigilancia).

- Ejercer un mayor control al agresor para evitar la impunidad penal en el incumplimiento del pago de las pensiones alimenticias (investigar su patrimonio cuando se declara insolvente).

- Incidir en la obligación de que el agresor acuda a programas de reeducación.

- Incidir en medidas de control judicial del agresor

\subsection{Sistema policial y medidas de protección}

- Hacer una evaluación de riesgo de cada caso y ofertar, si procede, medidas de protección policial específicas, al margen de si existe o no medida de protección judicial.

- Incidir en la formación y especialización de los y las agentes.

- Incidir en las medidas de protección, porque son vitales para las mujeres y dan resultados (pulsera, escolta).

- Proteger a las mujeres desde que ponen la denuncia hasta que se celebra el juicio rápido al día siguiente (acompañamiento de las mujeres, seguimiento de los agresores). 
- Informar a las mujeres sobre el ingreso en prisión del agresor en el mismo momento en el que se le informa a él, o previamente en el caso de las salidas y los permisos, para evitar riesgos.

- Adaptar las medidas de protección a cada caso concreto, previa evaluación específica.

\subsection{Sistema legislativo}

- Garantizar la ‘desvinculación’ económica posterior con el agresor (no estar obligada a asumir sus deudas económicas, por ejemplo).

- Crear un fondo de garantía social de las pensiones alimenticias (similar al Fogasa), para que no sean las mujeres quienes tengan que 'pelear' su cobro en los juzgados.

- Endurecer las condenas y garantizar su cumplimiento íntegro.

- Endurecer y ampliar las medidas penales y civiles contra el agresor.

- Denegar a los maltratadores la pensión penitenciaria.

- Cambiar la ley que impide que las mujeres divorciadas cobren la pensión de viudedad cuando han renunciado a la pensión compensatoria.

\subsection{Hijos e hijas a cargo}

- Priorizar los derechos de la infancia y la adolescencia (a no vivir en un entorno violento, a no correr riesgo) frente al derecho del padre a ver a sus hijos e hijas.

- Escuchar y atender las opiniones de los y las menores cuando se establecen convenios reguladores.

- Ofrecer apoyo psicológico para los y las menores (terapias individualizadas) y también para mayores de edad que hayan convivido durante la infancia con el agresor (porque son víctimas), en paralelo al proceso terapéutico de las madres.

- Limitar las visitas del agresor a los hijos e hijas, ya que con frecuencia la relación con el padre no es beneficiosa para ellos y ellas, y en muchos casos es contraproducente y contraria al apoyo terapéutico.

- Reconocer a los y las menores como víctimas directas de violencia de género, para establecer medidas de protección cuando puedan correr peligro.

- Impedir que los agresores puedan tener la patria potestad de sus hijos e hijas: primar la protección de los y las menores por encima de todo.

- Eliminar las consecuencias penales que pueden tener las mujeres cuando se niegan a que sus hijos/as vean al agresor.

\subsection{Ayudas sociales y económicas}

- Simplificar y agilizar la tramitación y resolución de ayudas.

- Considerar las situaciones propias de la violencia de género a la hora de establecer los requisitos que limitan el acceso a determinadas ayudas sociales de carácter general.

- Considerar de manera especial a las mujeres mayores de 50 años, por sus dificultades de incorporación al mundo laboral (por no haber cotizado suficiente, por tener problemas de salud o descendientes con discapacidad a cargo, por ejemplo).

- Ampliar la bolsa de viviendas de alquiler social, habilitando las viviendas actualmente vacías.

- Garantizar una vivienda de VPO en alquiler para las mujeres víctimas de violencia de género que lo necesiten.

- Incrementar las ayudas para el pago del alquiler de las VPO a las mujeres que lo necesiten.

- Incentivar la inserción laboral de las mujeres víctimas de violencia de género mediante medidas que fomenten su contratación.

- Facilitar la reinserción social de las mujeres víctimas de violencia de género mediante medidas que ya se emplean, por ejemplo, con las víctimas del terrorismo.

\section{Agradecimientos}

Como cierre a este artículo, es preciso dar las gracias a las mujeres que participaron en los grupos de trabajo y que, a través de sus relatos, hicieron posible un encuentro en el que compartir experiencias, con el fin último de reflexionar en torno a los obstáculos encontrados en su camino y de explicitar sus demandas. La normalización de sus vidas es un deseo para todas ellas, que algunas ya han conseguido y que otras pronto lo harán. A todas ellas, muchas gracias.

Vivir sin fobias, sin pastillas, sin complejos,... y ya después pensaré con quién [...]. No puedo pensar en lo bueno si primero no quito lo malo.

Vivir sin escudo, poder fiarme de otra persona.

Es precioso tener relaciones sexuales con alguien y no sentir asco ni miedo [...] [alguien] a quien puedas decir "hoy no me apetece", "hoy no quiero ir al cine...”.

Entendí que la culpa no era mía.

Estaba muy enfadada conmigo; ahora, me he reconciliado [conmigo misma].

Me gustaría algún día ser feliz. 
APARICI, E.; y ESTARELLAS, C. (2010): Historias de vida, historias de violencia. Si mi pareja me hace daño, ¿por qué sigo con ella?, Colección Intress, Aresta.

CANTERA, I.; ESTÉBANEZ, I.; y VÁZQUEZ, N. (2009): Violencia contra las mujeres jóvenes: la violencia psicológica en las relaciones de noviazgo, Bilbao Servicio de Mujer del Módulo Psicosocial de Deusto-San Ignacio.

DEPARTAMENTO DE ACCIÓN SOCIAL (2009): Violencia contra las mujeres en el ámbito doméstico. Resultados 2009 y comparativa 2005-2009 en el Territorio Histórico de Bizkaia, Bilbao, Diputación Foral de Bizkaia.

DIRECCIÓN DE ATENCIÓN A LAS VÍCTIMAS DE VIOLENCIA DE GÉNERO (2011a): I Plan de Actuación del Gobierno contra la Violencia de Género 2011-2013, Vitoria-Gasteiz, Gobierno Vasco.

- (2011b): Mujeres víctimas de la violencia de género en la CAPV. Informe anual 2010, Vitoria-Gasteiz, Gobierno Vasco.

EMAKUNDE (2014): VI Plan para la Igualdad de Mujeres y Hombres, Vitoria-Gasteiz, Emakunde.

ESPAÑA (2004): “Ley Orgánica 1/2004, de 28 de diciembre, de Medidas de Protección Integral contra la Violencia de Género", Boletín Oficial del Estado, n- 313, 29-12-2004, págs. 42.166-42.197.

EUSKADI (2012): “Ley 3/2012, de 16 de febrero, por la que se modifica la Ley para la Igualdad de Mujeres y Hombres y la Ley sobre Creación de Emakunde-Instituto Vasco de la Mujer", Boletín Oficial del País Vasco, nำ65, 16-3-2012, págs. 24.058-24.062.
- (2011): “Decreto 264/2011, de 13 de diciembre, por el que se crea el Observatorio Vasco de la Violencia Machista contra las Mujeres y se regula su funcionamiento y composición", Boletín Oficial del País Vasco, 28-12-2011, nํㅜ 245, 6.268.

- (2005): "Ley 4/2005, de 18 de febrero, del Parlamento Vasco para la Igualdad de Mujeres y Hombres", Boletín Oficial del País Vasco, no- 42, 2-3-2005, págs. 3.271-3268.

FUNDACIÓN EDE (2012a): Mujeres víctimas de violencia de género: vivencias y demandas, Vitoria-Gasteiz, Servicio Central de Publicaciones del Gobierno Vasco.

- (2012b): Violencia machista contra las mujeres en la CAPV: percepción, incidencia y seguridad, Vitoria-Gasteiz, Servicio Central de Publicaciones del Gobierno Vasco.

- (2010): La variable edad en la intervención con las mujeres víctimas de la violencia de género.

IBÁÑEZ GONZÁLEZ, M. (2004): Violencia doméstica en Euskadi: malos tratos a la mujer. Análisis y definición del proceso de ruptura con una relación de maltrato, Vitoria-Gasteiz, Servicio Central de Publicaciones del Gobierno Vasco.

INSTITUTO DE LA MUJER (2006): III Macroencuesta sobre la Violencia contra las Mujeres. Informe de resultados. Abril 2000, Madrid, Instituto de la Mujer.

ORGANIZACIÓN MUNDIAL DE LA SALUD (2005): Estudio multipaís de la OMS sobre salud de la mujery violencia doméstica contra la mujer: primeros resultados sobre prevalencia, eventos relativos a la salud y respuestas de las mujeres a dicha violencia: resumen del informe, Ginebra, Organización Mundial de la Salud. 
